Original Article

\title{
EVALUATION OF RADIO PROTECTIVE EFFECT OF AVERRHOA CARAM BOLA LEAVES EXTRACT IN WISTAR RATS
}

\author{
Arunachalam Kumarr, Suchetha Kumari N. ${ }^{2}$, Kavitha $\mathrm{K}^{3} \&$ Rojin T.S. ${ }^{4}$ \\ Professor \& Head ${ }^{1}$, Lecturer ${ }^{3}$, Department of Anatomy, Professor ${ }^{2}$, Department of Biochemistry, Lecturer ${ }^{4}$, \\ Department of Pharmacology, K.S. Hegde Medical Academy, Nitte University \\ M angalore - 575 018, Karnataka, India. \\ Correspondence: \\ Arunachalam Kumar \\ Professor \& Head, Department of Anatomy, K.S. Hegde Medical Academy, Nitte University, \\ Mangalore - 575 018, Karnataka, India. \\ M obile : +91 9972546264 Fax : 0824-2204162 E-mail : directorrd@ nitte.edu.in
}

\begin{abstract}
:
The present study was designed to investigate the radio protective efficacy of ethanolic extract of leaves of the Averrhoa carambola by studying the following parameters: radioprotective effect before and after radiation, estimating the Total Antioxidant Status, haematological parameters, assessing the histopathology of liver and kidney. Extract was given orally at a dose of $450 \mathrm{mg} / \mathrm{kg}$, orally for 15 days prior to and 15 days after radiation (2 Gy). The rats were kept under observation for 15 days for any sign of radiation sickness, morbidity, behavioural toxicity, urination and defecation pattern or mortality, which showed no changes. The haematological parameters showed a significant decrease in the irradiated rat when compared with the control group. Antioxidant activity revealed from the data obtained in the present study showed that A.carambola leaves ethanolic extract possess good antioxidant activity. Histopathological changes in the irradiated liver and kidney sections showed improved cellular architecture when compared to the normal. The present study suggests that supplementation with Averrhoa carambola has potent antioxidant activity and act as probable radioprotector against gamma radiation induced oxidative damage.
\end{abstract}

Keywords: Averrhoa carambola, radioprotection, Gamma-radiation, oxidative damage.

\section{Introduction:}

The use of plants as medicine is as old as human civilization. People of all ages in both developing and developed countries use plants in an attempt to cure various diseases and to get relief from physical sufferings.

Averrhoa carambola L. (star fruit, 'carambola' in Brazil) is a plant of the Oxalidaceae family. Originating from Asia, it can be found widely spread in tropical countries. In Brazilian folk medicine, its fruit, juice or tea prepared from its leaves, has been used for treating headache, vomiting, cough, insomnia, hypertension and diabetes [1-5].



limb numbness, muscle weakness, consciousness disturbance and seizure $[6,7]$.

Averrhoa carambola (oxalidaceae) also known as star fruit, is cultivated extensively in India for its edible fruits [8, 9]. In India the ripe fruit or the juice may be taken to counteract fever. In Ayurveda, the ripe fruit is considered as digestible, tonic strengthening and causes biliousness. The dried fruit is also used in the treatment of fever $[10,11]$ it is cooling and possesses anti-scorbutic properties. Fruit and its fruit juices are used as antioxidant and astringent [12].

The crushed leaves or shoots of Averrhoa carambola has been reported to be applied externally in the treatment of chicken pox, ring worm, tinea, cold and headache. Tea of boiled leaves is also used to relieve aphthous stomatitis and angina. A mixture of the leaves and fruits can be used to arrest vomiting and to treat fever. M oreover, leaves also find use in treating chronic conditions like oliguria, boils and pyodermas, postpartum oedema, gastroenteritis and 
traumatic injury [13].

The Oxalidaceae family possesses seven genera representing more than two hundred species which are distributed principally in the tropical and subtropical regions of the world [14]. The genus Averrhoa contains two species: carambola (Averrhoa carambola L.) and bilimbi (Averrhoa bilimbi L.). Carambola is also known as star fruit and is considered as the more important of the two species. The fruit is cultivated extensively in India and China [15]. Selection and improvement of cultivars was initiated in Florida in 1935 and by 1985, the fruit had attained the status of a popular commercial crop in the United State [16].

Radiation is present all around us, whether it is natural or man-made. Depending upon the type, intensity and duration, radiation exposure can pose a serious threat to an individual's survival. A numbe 
considerable decrease in superoxide dismutase and vitamin-C (Vit-C) in irradiated rats. There was a significant ameliorative effect in the levels of CHO, TG, HDL, LDL, VLDL, ALP, LDH and GGT, oxidative stress markers like M DA, CAT, SOD and Vit-C in irradiated animals given pre and postsupplementation with $\mathrm{N}$. jatamansi in comparison with control group [25].

Lipid peroxidation (LPO) - At all the post irradiation intervals lipid peroxidation remained significantly higher in the control group than normal one. The maximum lipid peroxidation level was observed at 7th day post irradiation. Then it decreased till the last interval. Lipid peroxidation level remained significantly lower in Punica granatum pretreated irradiated groups as compared to their respective controls at all the intervals. (Figure 2) Reduced glutathione (GSH) - Glutathione content decreased up till 7th day post irradiation. Glutathione content of the experimental group was found higher than the corresponding control group at all the intervals. (Figure 3) DNA content- DNA content remained significantly lower in control group as compared to the normal. After one day it decreased in Punica granatum pretreated irradiated group but it remained higher in comparison to control till 28th day [25].

This investigation was carried out to follow up radiation induced changes in brain of Wistar rats. Rats were randomly divided into 4 groups of 6 each. Three groups were irradiated with $5 \mathrm{y}, 7.5$ and $12 \mathrm{~Gy}$. The fourth group served as normal control. On the first day after the irradiation the animals were very lethargic. Mortality increased by 10 to 14 day. When the radiation increased to 7.5 GY somewhat different pattern of illness and death occurred. The animals in this group were severely injured by the day 3 to 4 . Loss of weight was pronounced and by the fifth day some of them were died. There was a sharp peak of mortality. None were survived beyond 2 weeks [26].

Mine et al conducted a study to assess the degree of protective effects of amifostine on kidney functions via semi quantitative static renal scintigraphy and histopathologic analysis. 30 female albino rats were divided into three equal groups as control (CL), radiotherapy alone (RT), and radiotherapy + amifostine (RT+AMI). The animals in the $\mathrm{CL}$ and $\mathrm{RT}$ groups were given phosphate-buffered saline, whereas the animals in the RT+AM I group received amifostine $(200 \mathrm{mg} / \mathrm{kg})$ by intra-peritoneal injection 30 min before irradiation. RT and RT+AMI groups were irradiated with a single dose of $6 \mathrm{~Gy}$ using a ${ }^{60} \mathrm{Co}$ unit at a source-skin distance of $80 \mathrm{~cm}$ to the whole right kidney. They were followed up for 6 months. CL, RT, and RT+AM I groups underwent static kidney scintigraphy at the beginning of the experiment and, again, on the day before sacrificing. Histo-pathologically, tubular atrophy and fibrosis of the kidney damage were evaluated [26].

The aim of the study was to assess the DNA damage progression with days after single exposure of 6Gy electron beam radiation (EBR). The animals were grouped into four. Group 1 served as control, Group 2, 3 and 4 were irradiated by 6 Gy EBR. Molecular DNA damage in lymphocytes of mice was assessed using alkaline comet assay and in bone marrow cells by micronucleus assay. In comet assay \% DNA in tail, Comet length, Olive Tail M oment (OTM ) served as a measure of DNA damage and in micronucleus test, frequency of micronucleus formation in bone marrow cells was measured to evaluate the DNA damage. An ionizing radiation induces approximately 1000DNA single strand break per cell, 4Gy gamma irradiation showed an average DNA tail length up to $22 \mu \mathrm{m}$ per cell. The observation based on the data obtained in the present study showed that irradiation with 6Gy EBR will induce about 200 $\mu$ m DNA tail length per cell on 15th post irradiation day [27].

All of the rats were anesthetized with an IP injection of ketamine $(50 \mathrm{mg} / \mathrm{kg})$ and chlorpromazine $(10 \mathrm{mg} / \mathrm{kg})$, and then the rats in groups 3 and 4 were exposed to a wholebody gamma radiation dose of $10 \mathrm{~Gy}$. Irradiation was performed using a cobalt-60 teletherapy unit (Theratron 780, Atomic energy of Canada limited, Canada) at a dose rate of $50 \mathrm{cG} /$ minute using the Single-wavelength anomalous dispersion method. Group 1 was the control group, group 2 only received melatonin $(30 \mathrm{mg} / \mathrm{kg}$ on the first day and $30 \mathrm{mg} / \mathrm{kg}$ ), group 3 only received whole body 
gamma irradiation of $10 \mathrm{~Gy}$, and group 4 received $30 \mathrm{mg} / \mathrm{kg}$ melatonin 30 minutes prior to radiation plus whole body irradiation of 10 Gy plus $30 \mathrm{mg} / \mathrm{kg}$ melatonin daily through intra-peritoneal (IP) injection for three days after irradiation. Three days after irradiation, all rats were sacrificed and their livers were excised to measure the biochemical parameters malondialdehyde (MDA) and glutathione (GSH). Ionizing radiation causes oxidative damage while melatonin, due to its anti-oxidative properties, ameliorates radiation induced injury to the rat liver [27].

An experiment was conducted to evaluate the effects of cobalt radiation in histo-morphology changes in heart, brain, kidney, spleen, lung and liver of Wistar rats weighing 160 to $180 \mathrm{gr}$. A total of 100 rats were divided into 4 groups with 25 rats each.T1) First group as control group did not receive any radiation, $\mathrm{T} 2$ ) was irradiated with 6Gy, T3) was irradiated with 8Gy, T4) was irradiated with 14Gy. The renal tissues were subjected to histo-pathological studies which revealed glomerular and tubular changes with infiltration of the neutrophils and other leukocytes.

Histo-pathological examination of the kidney revealed marked changes in tubules and glomeruli. The tubular epithelial cell were swollen with vaccuolation with numerous hyaline cast in the lumen. There were also severe atrophy and necrosis of the tubules in group three which received the highest dose of radiation. The pathophysiology of radiation nephritis is due to cellular injury caused by ionizing radiation [28].

Jagetia et al, conducted the study to investigate the radioprotective activity of a leaf extract of bael leaf (Aegle marmelos) (AME) in mice exposed to different doses of gamma-radiation. The mice were administered different

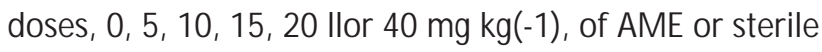
physiological saline intra-peritoneally once daily consecutively for 5 days before exposure to 10 Gy 60Co gamma-radiation or five doses of $15 \mathrm{mg} \mathrm{kg}(-1)$ AME before exposure to $6,7,8,9,10$ or $11 \mathrm{~Gy}$. The animals were monitored for symptoms of radiation sickness and mortality up to 30 days post-irradiation. Glutathione and lipid peroxidation were estimated in the surviving animals of both groups on day 31 post-irradiation [28].

To evaluate the effect of low-dose ( $<50 \mathrm{cGy}$ ) whole body irradiation on the antioxidant defence system in the liver and the lungs of mice at various post-irradiation intervals. Male Balb/c mice, 5 - 6 weeks of age, were divided into irradiated and non-irradiated groups. Whole body irradiation was done with gamma-rays from a (60) Co source at doses of 10, 25 and $50 \mathrm{cGy}$ (48.78 cGy/min). Lipid peroxidation and antioxidant status were measured in the liver and the lungs at 4, 12 and $24 \mathrm{~h}$ after irradiation. Lipid peroxidation increased by 1.38 and 2.0 fold in lung and liver respectively at $12 \mathrm{~h}$ after exposure to $25 \mathrm{cGy}$. Whole body exposure to 25 and $50 c G y$ significantly $(p<0.05)$ increased the hepatic reduced glutathione at $4 \mathrm{~h}$. Reduced glutathione continued to rise until $12 \mathrm{~h}$ and returned to the basal level at $24 \mathrm{~h}$, whereas in the lungs it remained elevated until $24 \mathrm{~h}$ at 10 and 25cGy. Antioxidant enzymes activities for superoxide dismutase, catalase, glutathione peroxidase and glutathione reductase increased by 1.22 , $1.13,1.22$ and 1.11 fold respectively $(p<0.05)$ in the liver at $4 \mathrm{~h}$ after exposure to $50 \mathrm{cGy}$ and remained elevated at almost the same level up to $12 \mathrm{~h}$ after exposure. Surprisingly these antioxidant defense enzymes remained unaltered in the lung at the above radiation doses. Lowdose whole body gamma-irradiation differentially modulates the antioxidant defense system in the liver and lungs of mice. The induction of endogenous glutathione, immediately after exposure to low-dose -irradiation, may be beneficial in protecting the cells from reactive oxygen species (ROS) induced oxidative stress [29].

Pharmacological profile: Leaf: Cabrini et al [25] reported that ethanolic extracts from A. carambola leaf and its butanol, ethyl acetate and hexane fractions are effective in reducing croton oil-induced ear edema and cellular migration in mice. These results support the popular use of this plant for skin inflammatory disorders. A large group of natural substances has demonstrated anti-inflammatory activity. As previously shown, A. carambola is rich in flavonoids and tannins [26]. 
These neurological events can be treated only by submitting the patients to haemodialysis. In spite of this therapeutic effort, many cases show a poor outcome which result in death [27-29]. A water-soluble neurotoxin was isolated from star fruit [30].This protein induced, convulsion in rats by acting on L-glutamate release as, demonstrated in synaptosomes prepared from the cerebral cortex [27]. These clinical and experimental effects motivated us to test some of the A.carambola extracts on the mammalian heart because folk medicine extensively uses teas and infusions obtained from carambola leaves.

Phytochemical analysis: In living systems, free radicals are constantly generated and they can cause extensive damage to tissues and biomolecules leading to various disease conditions, especially degenerative diseases, and extensive lysis [31]. Many synthetic drugs protect against oxidative damage but they have adverse side effects. An alternative solution to the problem is to consume natural antioxidants from food supplements and traditional medicines [32, 33]. Recently, many natural antioxidants have been isolated from different plant materials [34, 35].

The preliminary phyto-chemical screening tests may be useful in the detection of the bioactive principles and subsequently may lead to the drug discovery and development. Further, these tests facilitate their quantitative estimation and qualitative separation of pharmacologically active chemical compounds [36].

The present study determined the phyto-constituents and also the antioxidant capacity of A.carmbola leaves ethanolic extract by using three different assays. However, the efficiency of the extract differed against various free radicals depending on the specific assay methodology, which reflects the complexity of the mechanisms and diversity of the chemical nature of the plant material.

DPPH radical is commonly used as a substrate to evaluate antioxidant activity. It is a stable free radical that can accept an electron or hydrogen radical to become a stable molecule. The reduction of DPPH radical was determined by the decrease in its absorbance induced by antioxidants at $517 \mathrm{~nm}$. The lower the absorbance, the higher is the antioxidant activity of the test sample [37]. In this study, free radical scavenging activities of A.carambola leaves ethanolic extract and standard ellagic acid were determined by using DPPH method. The result obtained in the study indicates that the extract exhibited good radical scavenging activity but was to a lesser extent compared to standard ellagic acid.

\section{Aims \& objectives:}

The objectives of this study were to record the effect of ethanolic extract of leaves of the Averrhoa carambola $\mathrm{L}$. and to investigate the radio-protective effect, if any, Averrhoa carambola on male Wistar rats.

I Radio protective effect before and after radiation

I Estimation of Total Antioxidant Status.

I Assessment of nephritic damage by histopathology.

\section{Materials \& methods:}

Extract preparation: Averrhoa carambola leaves are collected during the month of March and April. The leaves were cleaned and powdered and used for the extraction. About 75 gms of powdered material was packed and thimble was prepared and extraction was carried out. The crude extract was obtained by macerating dry leaves in water: ethanol mixture for $72 \mathrm{hs}$ at $27 \pm 3^{\circ} \mathrm{C}$ using a Soxhlet apparatus. The solvents were then filtered and evaporated in a rotary evaporator and a crude extract was obtained. Each extract was concentrated in a rotary evaporator and stored in a dry environment.

Animal used: Albino rats (Wistar strain) of either sex (150$180 \mathrm{~g}$ ) will be obtained from the animal house of the institute. Animals will be kept in the animal caging system under the laboratory conditions $\left(25^{\circ} \pm 20^{\circ} \mathrm{C}, 12 \mathrm{hr}\right.$. Light). After a 7 days of acclimatization period, animal will be randomly selected for different experimental groups (6 animal/ group) and used for the in vivo determination of radio protective functions.

Irradiations: Rats were placed in well ventilated Perspex boxes. They were exposed to whole body irradiation from a 
$60 \mathrm{Co}$ source, at a dose rate of $2 \mathrm{~Gy} / \mathrm{min}$ and a source to surface distance of $100 \mathrm{~cm}$. The irradiated organs were Liver and Kidney. The facility was provided by Microtron Centre, $M$ angalore University.

Phytochemistry screening: The phyto-chemistry screening was performed on the A. carambola aqueous extract (AEx) by the Vasconcelos.et.al. (2005)

Aqueous extract fractionation: Five grams of the AEx was loaded on a $4 \times 80 \mathrm{~cm}$ silica gel 60 chromatographic column (Sigma- Aldrich, St. Louis, MO, USA). The column was eluted with a mixture of methanol and water with increasing polarity (100:0, 95.5, 90:10, 80:20, 50:50 and $0: 100, v / v)$.

Phytochemical studies: Preliminary phyto-chemical screening was reported ${ }^{7}$. The presence of phytoconstituents such as alkaloids, carbohydrates, flavonoids, steroids and resins were confirmed by previous studies.

Pharmacological screening: The animal experiments will be performed according to CPCSEA guidelines and after the approval from Institutional Animal Ethics Committee (I.A.C.E.), K. S. Hegde Medical Academy; experiments are conducted in accordance with the standard guidelines.

Collection and treatment of the biological samples: The rats were sacrificed under light anaesthesia and the blood was collected in the tubes containing 3.8\% sodium citrate by the cardiac puncture. A part of blood was used for haematological examination. Liver and Kidney was excised immediately. The tissue was then fixed in formalin solution for the histological examination. The tissues were then embedded in the paraffin wax and sections were cut. The sections were stained with haematoxylin and eosin $(\mathrm{H}$ and E), mounted with Canada balsam and were examined microscopically

Antioxidant activity: In living systems, free radicals are constantly generated and they can cause extensive damage to tissues and biomolecules leading to various disease conditions, especially degenerative diseases, and extensive lysis [31]. Many synthetic drugs protect against oxidative damage but they have adverse side effects. An alternative solution to the problem is to consume natural antioxidants from food supplements and traditional medicines [32, 33]. Recently, many natural antioxidants have been isolated from different plant materials $[34,35]$.

The preliminary phytochemical screening tests may be useful in the detection of the bioactive principles and subsequently may lead to the drug discovery and development. Further, these tests facilitate their quantitative estimation and qualitative separation of pharmacologically active chemical compounds. [36].

The present study determined the phyto-constituents and also the antioxidant capacity of A.carmbola leaves ethanolic extract by using three different assays. However, the efficiency of the extract differed against various free radicals depending on the specific assay methodology, which reflects the complexity of the mechanisms and diversity of the chemical nature of the plant material.

\section{DPPH assay}

Antioxidants react with DPPH, a stable free radical which is reduced to DPPH-H and as a consequence the absorbance is decreased from the DPPH radical to the DPPH-H form. The degree of discolouration indicates the scavenging potential of the antioxidant compounds or extracts in terms of hydrogen donating ability.

The free radical scavenging capacity of the A. carambola leaves ethanolic extract was determined using DPPH according to the method of Blois. DPPH solution $(0.004 \%$ $\mathrm{w} / \mathrm{v}$ ) was prepared freshly in $99 \%$ ethanol and was added to sample solution $(100 \mu \mathrm{g} / \mathrm{ml})$ in ethanol.The mixture was allowed to stand at room temperature in dark for 20 mins. Then the mixture was vortexed and the absorbance was read at $517 \mathrm{~nm}$ using a spectrophotometer. Ellagic acid was used as a reference standard. Control sample was prepared containing the same volume without any extract and $99 \%$ ethanol was used as blank. Lower absorbance of the reaction mixture indicated higher free radical scavenging activity. All tests were performed in duplicates. Percentage 
scavenging of the DPPH free radical was measured using the following equation, DPPH radical scavenging activity $(\%)=$ (Acontrol-ATest) /Acontrol X 100. Where A control is the absorbance of the control reaction and $A$ test is the absorbance in the presence of the extracts or standard.

Hydroxyl radical scavenging assay: This was assayed as described by Elizabeth and Rao [11] with a slight modification. The assay is based on quantification of the degradation product of 2-deoxyribose by condensation with TBA. Hydroxyl radical was generated by the $\mathrm{Fe}^{3+}$ ascorbate-EDTA- $\mathrm{H}_{2} \mathrm{O}_{2}$ system (the Fenton reaction). The reaction mixture contained, in a final volume of $1 \mathrm{ml}, 2$ deoxy-2-ribose (2.8 mM); $\mathrm{KH}_{2} \mathrm{PO}_{4}-\mathrm{KOH}$ buffer $(20 \mathrm{mM}$, pH 7.4); $\mathrm{FeCl}_{3}(100 \mu \mathrm{M}) ;$ EDTA $(100 \mu \mathrm{M}) ; \mathrm{H}_{2} \mathrm{O}_{2}(1.0 \mathrm{mM})$; ascorbic acid $(100 \mu \mathrm{M})$ and various concentrations (0-200 $\mu \mathrm{g} / \mathrm{ml}$ ) of the test sample or reference compound. After incubation for $1 \mathrm{~h}$ at $37^{\circ} \mathrm{C}, 0.5 \mathrm{ml}$ of the reaction mixture was added to $1 \mathrm{ml} 2.8 \%$ TCA, then $1 \mathrm{ml} 1 \%$ aqueous TBA was added and the mixture was incubated at $90^{\circ} \mathrm{C}$ for $15 \mathrm{~min}$ to develop the color. After cooling, the absorbance was measured at $532 \mathrm{~nm}$ against an appropriate blank solution. Reaction mixture without test substances/extracts was used as control. All tests were performed in duplicates. Ellagic acid, a classical $\mathrm{OH}$ scavenger, was used as a positive control. Lower absorbance of the reaction mixture indicated higher $\mathrm{OH}$ radical scavenging activity. Percentage inhibition was evaluated by comparing the test and blank solutions. Percentage scavenging of the $\mathrm{OH}$ radical was measured using the following equation, $\mathrm{OH}$ radical scavenging activity $(\%)=\left(A_{\text {control }}-A_{\text {test }}\right) / A_{\text {control }} \times 100$. Where $A_{\text {control }}$ is the absorbance of the control reaction and $A_{\text {test }}$ is the absorbance in the presence of the sample or the extract.

Reducing power (FRAP) assay: The Fe ${ }^{3+}$-reducing power of the extract was determined by the method of Oyaizu ${ }^{[12]}$ with a slight modification. Different concentrations $(0$ $400 \mu \mathrm{g} / \mathrm{ml})$ of the extract $(0.5 \mathrm{ml})$ were mixed with $0.5 \mathrm{ml}$ phosphate buffer $(0.2 \mathrm{M}, \mathrm{pH} 6.6)$ and $0.5 \mathrm{ml}$ potassium hexacyanoferrate $(1 \%)$, followed by incubation at $50^{\circ} \mathrm{C}$ in a water bath for $20 \mathrm{~min}$. After incubation, $0.5 \mathrm{ml}$ of TCA (10\%) was added to terminate the reaction. The upper portion of the solution $(1 \mathrm{ml})$ was mixed with $1 \mathrm{ml}$ distilled water, and $0.1 \mathrm{ml} \mathrm{FeCl}{ }_{3}$ solution (0.1\%) was added. The reaction mixture was left for $10 \mathrm{~min}$ at room temperature and the absorbance was measured at $700 \mathrm{~nm}$ against an appropriate blank solution. All tests were performed in duplicates. A higher absorbance of the reaction mixture indicated greater reducing power. Ellagic acid was used as a positive control.

Experimental Animal: Albino rats (Wistar strain) of either sex (150-200gms) and of approximately the same age and weight were procured from KSHEMA animal house were used for the study. They were kept in animal caging system and provided with standard animal feed pellets and water ad libitum. Animals were randomly selected for different experimental groups and used for the in vivo determination of Radio protective activity. All experiments were performed according to the norms of the ethical committee.

\section{Acute toxicitystudy}

The animals required are 24 mice. The ethanolic leaf extract of Averrhoa carambola when orally given to the rats at doses from 200 to $1000 \mathrm{mg} / \mathrm{kg}$ showed no mortality or any adverse signs with regard to body weight, body temperature, and food and water uptake during the first $2 \mathrm{~h}$ and no mortality was observed till $24 \mathrm{hr}$. The dosage taken for this study is fixed as $450 \mathrm{mg} / \mathrm{kg}$ body weight orally.

Experimental animals were distributed randomly in four groups containing sixanimals each. (Table I)

Group I- these are the control animals which contained abouteach.

Group II - Animals received only radiation.

Group III - Animals were pretreated with extract for 15 days and then was subjected for radiaton

Group IV- Animals were first subjected to radiation and then treated with plant extract for 15 days. 
Table: I

\begin{tabular}{|l|c|}
\hline GROUPS & NO. OF RATS \\
\hline GROUP I & 6 \\
\hline GROUP II & 6 \\
\hline GROUP III & 6 \\
\hline GROUP IV & 6 \\
\hline
\end{tabular}

Whole body radiation: The animals will be exposed to required dosage of whole body radiation.

The animal will be observed for 15 days for any sign of radiation sickness, morbidity, behavioural toxicity, urination and defecation pattern or mortality.

Haematological studies: The total cell count is taken by counting the number of cells in all four W.B.C chambers and an average number of cells per $\mathrm{mL}$ is calculated using the formula: Numbers of cells in 4 chambers $\times$ dilution $\times 10^{4}$.

Total antioxidant capacity (T-AOC): M easurement of serum total antioxidant capacity level is reported to provide an integrated index, as opposed to one based on simple summation of measurable antioxidants (Huango, 2005). It possibly could be used to assess the real change in antioxidant status in patients with severe sepsis and might lead to universally useful treatment. Serum total antioxidant capacity is commonly assessed using the spectrophotometric assay, also called "Trolox equivalent antioxidant capacity" assay (Rice- Evans \& Miller 1994 Moore et al. 1994).

Thiobarbituric acid- reactive substances (TBARS); Lipid peroxidation refers to the oxidative degradation of lipids. It is the process whereby free radicals "steal" electrons from the lipids in cell membranes, resulting in cell damage. This process proceeds by a free radical chain reaction mechanism. Markers of lipid peroxidation, called thiobarbituric acid-reactive substances (TBARS), are measured in plasma using a fluorometric technique.

$M$ alonaldehyde, a secondary product of lipid peroxidation, reacts with thiobarbituric acid (TBA) in the presence of acidic medium to give a pink colour pigment at 97 degrees at $\mathrm{pH} 2-3$. The pink colour is extracted with butanol and absorbance read at $532 \mathrm{~nm}$ (Ohkawa et al. 1979),
Wasowicz.et al. 1993).

Superoxide dismutase (SOD): The enzyme superoxide dismutase (SOD, EC 1.15.1.1), catalyzes the dismutation of superoxide into oxygen and hydrogen peroxide. As such, it is an important antioxidant defence in nearly all cells exposed to oxygen. Several common forms of SOD exist: they are proteins co factored with copper and zinc, or manganese, iron, or nickel. Superoxide is one of the main reactive oxygen species in the cell and as such, SOD serves a key antioxidant role.

The principal of SOD activity assay is based on the inhibition of nitroblue tetrazolium (NBT) reduction. The reduction of NBT by superoxide radicals to blue coloured formazon was followed at 565nm (Misra and Fridovich, 1972). This is followed by the inhibition of CuZnSOD with KCN (Geller and Winge, 1983) and subsequent measurements of the remaining enzymatic activity, which was attributed to M nSOD.

Treatment of Rat with A. carambola leaf extract and survival studies: To determine whether A. carambola conferred an advantage after lethal irradiation, the effect of $A$. carambola on the survival of rat was investigated. The extract were administered orally daily at doses of 200, 400 and $800 \mathrm{mg} / \mathrm{kg}$ bd. wt. to animals for 15 consecutive days before irradiation for pre-radiation group. For the post radiation group, the animals were first subjected to radiation and then were given with the extract for next 15 days. The number of surviving mice was recorded daily up to 30 days post-irradiation.

All the mice in the experiments were randomly divided into six groups as follow: Group I (control) and II (radiation alone) orally received normal saline but no extract; Group III was given with extract + radiation; Group IV was radiation plus extract; each group consisted of 6 rats.

Hematological study: Experimental grouping and treatment used for periphery blood analysis consulted in previous paragraph. After completion of the experiment, the animals are sacrificed by anaesthetising the animals with chloroform and the blood was collected by cardiac 
puncture, the blood was then transferred to vials for necessary haematological studies. The total numbers of RBC, WBC, platelets and the haemoglobin level were determined using standard procedures.

Histopathological study; In the histological studies, portions of liver and kidney tissue were fixed with $10 \%$ formalin, dehydrated in graded (50-100\%) alcohol and embedded in paraffin. Thin sections (4-5 Im) were cut and stained with haematoxylin and eosin (H\&E) stains. They were analyzed by a light microscope and images were captured with a digital camera. The animals were subjected to radiation at the dose of 2Gy's for kidney and liver and then were studied for the changes.

Statistical analysis: Results are reported as means \pm S.D. The program Graph Pad Prism is used. Data were analyzed statistically by the unpaired Student's t-test or one way ANOVA and $p<0.05$ was accepted for all comparisons.

\section{Results \& discussion :}

Antioxidant properties: Reducing power Assay

The extract showed potent antioxidant power by reducing power ability. The reducing capacity of the compound served as an indicator of its potential antioxidant activity. Results of reducing power assay are shown in table 1.The EC50 value of the extract and standard were found to be $505.31 \pm 1.42 \mu \mathrm{g} / \mathrm{ml}$ and $104.88 \pm 0.92 \mu \mathrm{g} / \mathrm{ml}$ respectively.

Hydroxyl radical scavenging activity

Hydroxyl radical scavenging assay shows the ability of the extracts and standard Ellagic acid to inhibit hydroxyl radical-mediated deoxyribose degradation in a $\mathrm{Fe}^{3+}$-EDTA-ascorbic acid and $\mathrm{H}_{2} \mathrm{O}_{2}$ reaction mixture. The results of the assay are shown in Table II. The percentage of radical scavenging property of the extract and standard in this assay were $25.38 \pm 1.50 \%$ and $88.79 \pm 0.70 \%$ at $200 \mu \mathrm{g} / \mathrm{ml}$ respectively.

DPPH radical scavengingassay

DPPH is stable free radical with deep purple color, after receiving proton from a proton donor such as phenolic compounds, it loses its chromophore and becomes yellow.

The results of the assay are given in the tablel. The percentage of radical scavenging property of the extract and standard in this assay were $32.83 \pm 0.43 \%$ and $93.70 \pm$ $0.70 \%$ at $100 \mu \mathrm{g} / \mathrm{ml}$ respectively.

\section{Table III :RBC SOD Activity}

\begin{tabular}{|l|l|l|}
\hline GROUPS & SOD ACTIVITY & SD \\
\hline PRE RADIATION & 30.98574624 & 5.93488 \\
\hline POST RADIATION & 34.73946948 & 7.580216 \\
\hline
\end{tabular}

Rats exposed with pre radiation group showed a significant decrease in erythrocytes SOD activity as compared to post radiation group. (Table III)

Effect of extract treatment on haematological parameters:

The haematological parameters of rats against gamma irradiation damage are depicted in the Table below. The WBC, erythrocytes, Packed cell volume and haemoglobin content decreased significantly $(P<0.001)$ in gamma irradiated rats (Group 2) as compared to the control (Group 1). The platelet count was more than control group as compared to pre-radiated and postradiated group. These comparisons are depicted in a graph (Figure 3\& Table IV)

Table IV: Comparison of other haematological parameters between pre-radiated \& post-radiated group:

\begin{tabular}{|l|l|l|}
\hline PARAM ETERS & PRE RADIATION & POST RADIATION \\
\hline $\mathrm{LY}^{*} 10^{3} / \mu \mathrm{l}$ & $1.95 \pm 0.64$ & $1.97 \pm 0.76$ \\
\hline $\mathrm{M} 0^{*} 10^{3} / \mu \mathrm{l}$ & $0.033 \pm 0.058$ & $0.2 \pm 0.18$ \\
\hline $\mathrm{GR} * 10^{3} / \mu \mathrm{l}$ & $0.17 \pm 0.12$ & $0.23 \pm 0.25$ \\
\hline $\mathrm{RBC} * 10^{6} / \mu \mathrm{l}$ & $4.6966667 \pm 0.65$ & $5.87 \pm 0.39$ \\
\hline $\mathrm{LY} \%$ & $83.67 \% \pm 0.093725$ & $82.47 \% \pm 0.109$ \\
\hline $\mathrm{M} 0 \%$ & $3.50 \% \pm 0.03$ & $7.60 \% \pm 0.055$ \\
\hline $\mathrm{GR} \%$ & $9.50 \% \pm 0.07$ & $9.93 \% \pm 0.058$ \\
\hline $\mathrm{HCT}(\%)$ & $32.63 \% \pm 0.44$ & $36.13 \% \pm 0.026$ \\
\hline $\mathrm{MCV}(\mathrm{fl})$ & $69.47 \% \pm 2.53$ & $61.5 \% \pm 3.074$ \\
\hline $\mathrm{MCCH}(\mathrm{pg})$ & $22.47 \% \pm 0.72$ & $20.02 \% \pm 1.2$ \\
\hline MCHC(g/dl) & $32.27 \% \pm 0.50$ & $32.81 \% \pm 0.37$ \\
\hline RDW $(\%)$ & $16.53 \% \pm 0.004$ & $14.78 \% \pm 0.001$ \\
\hline PCT & $0.34 \% \pm 0.001$ & $0.36 \% \pm 0.001$ \\
\hline M PV(fl) & $7.2 \pm 0.7$ & $6.67 \pm 0.2$ \\
\hline PDW(fl) & $7.7 \pm 0.7$ & $7.62 \pm 0.67$ \\
\hline
\end{tabular}




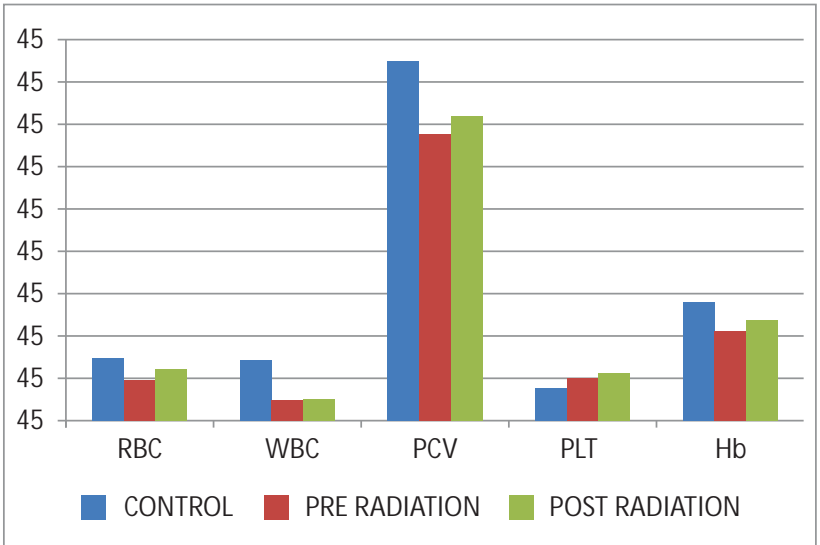

Figure 3: Graphical representation of Control, Pre-radiation and Post-radiation groups
Histo-pathological changes in the kidney sections stained with haematoxylin and eosin showed normal glomerular apparatus and tubular systems. The pre- radiated group showed more distortion of the glomerular apparatus. Post treated group resulted in decreased changes in the kidney tubules as compared to Pre- treated group. (Figures $1 \& 2$ )

Our results show that irradiation, induced damage to the hepatic and kidney tissues. Averrhoa carambola extract probably through its free radical scavenging property has shown recovery of the distorted tissues to some extent. Hence it can be concluded that extract may be useful as a



Figure: 1 A



Figure: 1 B



Figure: $1 \mathrm{C}$

Figure 1 : H\& E Sections of liver of controls (1A). Liver of pre-radiation group rats (1B). Liver of post-radiated group rats (1C) (under $10 \mathrm{X}$ )



Figure: 2 A

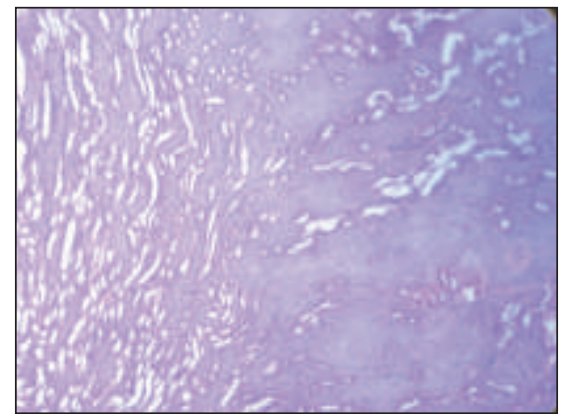

Figure: 2 B

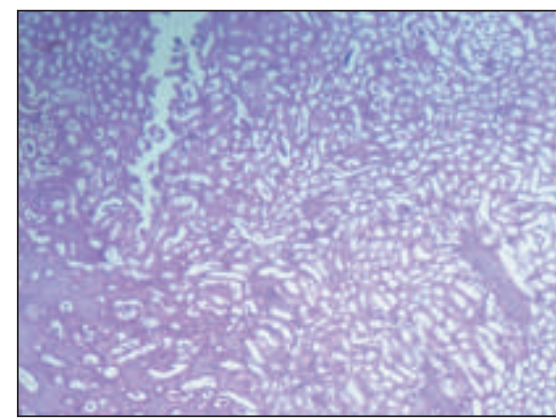

Figure: $2 \mathrm{C}$

Figure 2 : $\mathrm{H} \& \mathrm{E}$ sections of kidney control (2A). Kidney of pre-radiation group rats (2B) Kidney of post-radiation group (2C) (under 10X)

Effect of extract on histology of rat liver and kidney:

The control animals (Group 1) showed normal cellular characteristics of liver, i.e., normal parenchyma, well preserved lobules, normal hepatocytes and capsules with no evidence of adhesion and inflammation. The liver histology of the rats exposed with gamma irradiation at a dose of 2.0 Gy's (Group 2), revealed haemorrhage involving small hepatic veins. The histology of liver of the rats treated with extract for 15 days prior post radiation (Group IV) showed normal cellular architecture than pre-radiated group (Group III) architecture. good antioxidant and radio-protector.

\section{Acknowledgements:}

The authors thank the Research \& Recognitions Committee, Nitte University, Mangalore, for funding this project and the Nitte University Center for Science Education \& Research (NUCSER) for extending facilities for conducting the study. 
References:

1. Oliveira VPV, Cavalcanti FS, Bezerra CLF \& Pinto JL (1989). Plantas medicinais: consideracoes ecologicas e uso popular. Salusvita, 8: 4958.

2. Pio-Correa M (1931). Dicionário de Plantas Úteis do Brasil. Ministério da Agricultura, Brasília, DF, Brasil.

3. Muir CK \& Lam CK (1980). Depressant action of Averrhoa carambola. Medical Journal of M alaysia, 34: 279-280.

4. M artha RCD, Poubel J, Ferreira LCL, Lima RS, Borrás MR, Costa PRC \& Roland IA (2000). Atividade hipoglicêmica de Averrhoa carambola L. usada em M anaus como antidiabético. NewsLab, 38: 142-148.

5. Padmawinata K \& Hoyaranda E (1980). The effect of the juice of Averrhoa carambola fruit and the aqueous extract of Persia Americana leaves on rat blood pressure. 4th Asian Symposium on Medicinal Plants and Spices, Bangkok, Thailand, 159 (Abstract).

6. Neto M M , Costa JA, Garcia-Cairasco N, Netto JC, Nakagawa B \& Dantas M (2003). Intoxication by star fruit (Averrhoa carambola) in 32 uremic patients: treatment and outcome. Nephrology, Dialysis, Transplantation, 18: 120-125.

7. Tse K-C, Yip P-S, Lam M-F, Choy B-Y, Li F-K, Lui S-L, Lo W-K, Chan T-M \& Lai K-N (2003). Star fruit intoxication in uremic patients: case series and review of the literature. Internal M edicine Journal, 33: 314-316.

8. Cooke T, The Flora of the Presidency of Bombay, Botanical Survey of India, 1961;1: Calcutta.

9. Flora: A Gardener'sEncyclopedia: 2004; 1: Garden Cheers Publishing.

10. Kirtikar K.R. and Basu. B.D.: Indian Medicinal Plants: 1989;1: 2nd Edition . Published by Lalit M ohan Basu Allahabad, India.

11. Parrotta J.A. Healing Plants of Peninsular India, 2001;CABI Publishing, USA.

12. Md. Masum Mia, M ohmad S. Rahman, Kohinur Begum, Bilkis Begum and M ohammad A. Rashid:J.Pharm. Sci. 2007; 6(2): 125-128.

13. Chung KS, Paul P H,Kimura T.International Collation of Traditional and folk medicine: Northeast Asia.1998:75.

14. Hayes WB. Fruits growing in India. Allahabad: Kitabistan; 1960.

15. Campbell CW, Knight RJ, Olszack R., Carambola production in Florida. Proc. Fla. State Hort. Soc. 1985; 98:145- 149.

16. Campbell CW. Tropical fruit crops in Florida: A rapidly changing situation. Proc. Fla. Sate Hort. Soc. 1986; 99:217-219.

17. Morton J. Carambola. In: Fruits of warm climates. Julia F. Morton, Miami, FL; 1987. p. 125-128. (17)

18. Sheth A. The Herbs of Ayurveda. Ashok K. Sheth, publisher; 2005. Vol 1 p. 140. (18)

19. Kirtikar KR, Basu BD. Indian Medicinal Plants. Vol. 1. Second Edition. Published by Lalit M ohan Basu; 1984.

20. Wealth of India: A Dictionary of Indian Raw Materials and Industrial Products. Delhi: Council of Scientific and Industrial Research; 1948.

21. Kirtikar KR, Basu BD. Indian Medicinal Plants. Vol. 1. Second Edition. Published by Lalit M ohan Basu; 1984

22. Martha RCD, Poubel J, Ferreira LCL, Lima RS, Borrás M R, Costa PRC, Roland IA. Atividade hipoglicêmicade Averrhoa carambola L. usada em M anaus como antidiabético. NewsLab. 2000; 38:142-148.
23. Ferreira EB, Fernandes LC, Galende SB, Cortez DAG, Bazotte RB. Hypoglycemic effect of the hydroalcoholic extract of leaves of Averrhoa carambola L. (Oxalidaceae). Brazilian Journal of Pharmacognosy. 2008; 18(3):339-343.

24. Vasconcelos CML, Araujo MS, Silva BA, Conde-Garcia EA. Negative inotropic and chronotropic effects on the guinea pig atrium of extracts obtained from Averrhoa carambola L. leaves. Braz. J. Med. Biol. Res. 2005; 38(7):1113-1122.

25. Cabrini DA, Moresco HH, Imazu P, Delai da Silva C, Pietrovski EF, Gasparin DA, Mendes B, Prudente A, Pizzolatti MG, Brighente IMC, Otuki M F. Analysis of the Potential Topical Anti-Inflammatory Activity of Averrhoa carambola L. in Mice. Hindawi Publishing Corporation. Evidence- Based Complementary and Alternative Medicine. 2010; Volume 2011, Article ID 908059, 7 pages doi:10.1093/ecam/neq

26. Thomas S, Patil DA, Patil AG, Naresh Chandra. Pharmacognostic evaluationand physicochemical analysis of Averrhoa carambola $\mathrm{L}$. fruit. Journal of Herbal M edicine and Toxicology. 2008; 2(2):51-54.

27. Neto M M , Robl F \& Netto JC (1998). Intoxication by star fruit (Averrhoa carambola) in six dialysis patients. Nephrology, Dialysis, Transplantation, 13: 570-572.

28. Chang J-M , Hwang S-J, Kuo H-T, Tsai J-C, Guh JY, Chen H-C, Tsai J-H \& Lai $\mathrm{Y}-\mathrm{H}$ (2000). Fatal outcome after ingestion of star fruit (Averrhoa carambola) in uremic patients. American Journal of Kidney Diseases, 35: 189-193.

29. Chang CT, Chen YC, Fang JT \& Huang CC (2002). Star fruit (Averrhoa carambola) intoxication: an important cause of consciousness disturbance in patients with renal failure. Renal Failure, 24: 379-382.

30. Cecchini AL, Fontana ACK, Beleboni RO, Pizzo AB, Santos WF, Thomazini JA, Neto MM \& Coutinho-Netto J (1999). Purification and biochemical characterization of a convulsant neurotoxin from the star fruit (Averrhoa carambola): specific neurotransmitter release on rat cerebral cortex synaptosomes. Presented at the XIV Annual Meeting of the Federação de Sociedades de Biologia Experimental, Caxambu, M G, Brazil, August 25-28, Abstract 12.193.

31. Halliwell B, Gutteridge JM. Free radicals in biology and medicine Oxford: Oxford University Press; 1998.

32. Yazdanparast $\mathrm{R}$, Ardestani $A$. In vitro antioxidant and free radical scavenging activity of Cyperus rotundus. J Med Food 2007; 10: 667674.

33. Yazdanparast R, Bahramikias S, Ardestani A: Nasturtium oficinale reduces oxidative stress and enhances antioxidant capacity in hypercholesterolaemic rats. Chem Biol Interact 2008; 172:176-184.

34. P. Varadarajan, G. Rathinaswamy, and D. Asirvatahm. Antimicrobial properties and phytochemical constituents of Rheo discolor Ethnobotanical Leaflet.2008; 12: 841-845.

35. L, Ong ASH.Biological oxidants and antioxidants: Molecular mechanisms and health effects Champaign, 1997; IL: AOCSPress.

36. Jovanovic SV, Simic MG: Antioxidants in nutrition. Ann NY Acad Sci 2000; 899: 326-334.

37. Arnao M.B,Cano and M.Acosta..The hydrophilic and lipophilic contribution to total antioxidant activity, Food Chem, 2001; 73: 239244. 